\title{
The Effect of Job Flexibility on Female Labor Market Outcomes: Estimates from a Search and Bargaining Model ${ }^{\ddagger}$
}

\author{
Luca Flabbi ${ }^{\S}$ \\ Georgetown University \\ Andrea Moro \\ Vanderbilt University
}

February 10, 2011

\begin{abstract}
In this article, we develop a search model of the labor market in which jobs are characterized by work-hours flexibility. Workers value flexibility, which is costly for employers to provide. We estimate the model on a sample of women extracted from the CPS. The model parameters are empirically identified because the accepted wage distributions of flexible and non-flexible jobs are directly related to the preference for flexibility parameters. Results show that more than one-third of women place a small, positive value on flexibility. Women with a college degree value flexibility more than women with only a high school degree. Counterfactual experiments show that flexibility has a substantial impact on the wage distribution but a negligible impact on the unemployment rate. These results suggest that wage and schooling differences between males and females may be importantly related to flexibility.
\end{abstract}

\section{Introduction}

Anecdotal and descriptive evidence suggests that work hours' flexibility, such as the possibility of working part-time or choosing when to work during the day, is a job amenity women particularly favored when interviewed about job conditions. ${ }^{1}$ On average, women

\footnotetext{
${ }^{\ddagger}$ We would like to thank the editor, two anonymous referees, conference participants at the 2010 SITE Conference on Women and the Economy (Palo Alto, CA), the 2009 IZA Conference on Labor Market Policy Evaluation (Washington, DC), the 2007 Conference on Auctions and Games (Blackburg, VA), the 2006 SED Conference (Vancouver, CA) and seminar participants at Bocconi University (Milan, Italy), Collegio Carlo Alberto (Turin, Italy), GRIPS (Tokyo, Japan), and Johns Hopkins (Baltimore, MD) for many useful comments.

$\S^{\S}$ Department of Economics, Georgetown University and IZA, If74@georgetown.edu.

『Department of Economics, Vanderbilt University, andrea@andreamoro.net

${ }^{1}$ See, for example, Scandura and Lankau (1997).
} 
spend more time in home production and child-rearing and less in the labor market. ${ }^{2}$ In this paper, we measure women's preference for job flexibility and its effects on labor market outcomes by estimating the parameters of a search and matching model of the labor market with wage bargaining. We show how preferences for flexibility affect labor market outcomes and the shape of the accepted wage distribution. Finally, we assess the welfare and labor-market implications of policies favoring job flexibility.

We describe the model in Section 3. Jobs can be flexible or not, and flexible jobs are more expensive to provide. ${ }^{3}$ Workers have preferences for wages and flexibility and meet with firms to bargain over these dimensions. Wage heterogeneity arises from the bargaining process as a result of idiosyncratic match-specific productivity and heterogeneity in preferences for flexibility. We show that because of search frictions, the wage differential between flexible and non-flexible jobs is not a pure compensating differential. ${ }^{4}$

In Section 4 we discuss the identification of the model parameters with data on wages and job flexibility. The model predicts wage distributions for flexible and non-flexible jobs. To provide intuition for the parameter identification, we show that if all the workers have the same preferences for flexibility then the accepted wage distributions of flexible and non- flexible jobs have non-overlapping supports. The size of the gap is measured by the monetary value of the preference for flexibility, which is equivalent to the compensating wage differential paid to the worker that marginally rejects a flexible job over a non-flexible job. Preferences for flexibility also imply a wider support of the wage distribution of flexible jobs. The firms' cost of providing flexibility is also identified because a higher cost implies fewer flexible jobs in equilibrium.

We describe the data in Section 5. Working hours' flexibility includes both the possibility of working fewer hours and the option of organizing the working hours in a flexible way. Some papers focus on the first type of flexibility by studying part-time work and hourswage trade-offs. ${ }^{5}$ Data limitations make it difficult to study the second type of flexibility. Although our model and estimation method apply to a general definition of flexibility, our

\footnotetext{
${ }^{2}$ For example, using the 2008 March Current Population Survey (CPS), a representative sample of U.S. workers, we find that more than 20 percent of women with a college degree work less than 30 hours per week, while only 1.6 percent of men in the same demographic group do so. Data from the 2008 American Time Use Survey show that women spend approximately 60 percent more time than men do in family-related activities during the work day. Women also generally choose jobs with a more flexible working schedule (Golden 2001).

${ }^{3}$ This cost can be justified on the grounds that flexibility may require hiring a higher number of workers, which implies greater search and training costs. In addition, flexible schedules make it more difficult to coordinate workers engaged in a common task.

${ }^{4}$ It is a compensating differential only for the marginal worker that who is indifferent toward the dissimilarity between a flexible and a non-flexible job.

${ }^{5}$ See, for example, Altnoji and Paxson (1988) and Blank (1990).
} 
data force us to approximate flexible jobs as part-time jobs. In the empirical implementation, we define a job as flexible when the worker provides less than 35 hours of work per week.

Section 6 describes our estimation strategy. Our estimation approach uses a simulated method of moments to minimize a loss function that includes several moments of the wage distributions of flexible and non-flexible jobs and moments of the distribution of unemployment durations. The parameter estimates show that approximately 37 percent of college-educated women have a positive preference for flexible jobs, valued between 1 and 10 cents per hour, but only about 20 percent of them choose such jobs in equilibrium. The value of flexibility for women with at most a high school degree is estimated to be equal to or less than 2.5 cents per hour.

The structural-model estimates allow us to evaluate policy interventions, which we present in Section 8. We assess the welfare effects of the flexibility option by comparing our estimated model with an environment in which flexibility is not available. Next, we analyze a policy that reduces the cost of providing flexibility. Because of equilibrium effects, if flexibility is more costly or not available, some individuals observed in flexible jobs might decide to work in non-flexible jobs, whereas others might decide to remain unemployed. These workers preferences and productivities are relevant to assess each policy's overall labor market effect. Search frictions and preferences over job amenities also imply that policy intervention may improve welfare because the compensating differentials mechanism is only partially at work. ${ }^{6}$

These counterfactual experiments suggest that flexibility has a large impact on the accepted wage distribution. However, the impact on overall welfare and unemployment is very limited. This implies that if men had significantly lower preferences for flexibility - as some anecdotal evidence seems to indicate - then these policies would have the potential to reduce the gender wage gap without significantly affecting overall welfare.

\section{The existing literature and our contribution}

A vast amount of literature estimates the marginal willingness to pay for job attributes using hedonic wage regressions. ${ }^{7}$ Various authors have recognized the limitation of the static labor market equilibrium that provides the foundation for this approach. One alternative approach, the use of dynamic hedonic price models (see, e.g., Topel 1986), maintains the

\footnotetext{
${ }^{6}$ Hwang, Mortensen and Reed (1998) and Lang and Majumdar (2004) prove this argument formally.

${ }^{7}$ Rosen (1974) provides one of the first and most influential treatment of the issue. See Rosen (1986) for a more recent survey.
} 
static framework assumption of a unique wage at each labor market for given observable variables.

However, if there are frictions that make the market noncompetitive, hedonic wage regressions produce biased estimates. The bias arises for two reasons. First, flexibility is a choice; therefore, a selection bias may arise if we do not observe the wage that workers choosing flexible jobs would receive had they chosen a different type of job. This bias can be identified by observing the wage pattern of workers that make different flexibility choices over their career, but few workers change their flexibility choice over their lifetime. Moreover, it is crucial in this approach to control appropriately for job market experience, but it is difficult to do so if experience is a choice that is affected in part by preferences for flexibility. Our approach is to model the selection so that parameters can be identified by the entire shape of the distributions of wages and unemployment durations.

The second type of bias arises because in hedonic wage models the compensating differential mechanism is working perfectly so that the conditional wage differential is a direct result of preferences. Hwang, Mortensen, and Reed (1998) construct a search model of the labor market showing how frictions interfering with the compensating differential mechanism may bias the estimates from an hedonic wage model.The bias may be so severe that the estimated willingness to pay for a job amenity may have the wrong sign. In an hedonic wage model, a job amenity is estimated to convey positive utility only if the conditional mean wage of jobs with the amenity is lower than the conditional mean wages of jobs without the amenity. However, in an environment with on-the-job searching and wage posting, firms may gain positive profit by offering both a higher wage and the job amenity because doing so will reduce worker turnover. The observed wage distribution may then exhibit a positive correlation between wages and the job amenity even if workers are willing to pay for it. ${ }^{8}$

In our model, we obtain a similar outcome without on-the-job searching and wage posting as a result of bargaining. When workers and employers meet, they observe a matchspecific productivity draw and then engage in bargaining over wages and job amenities. The relationship between productivity and wages depends on preferences for the job amenity in two ways: directly, because of the compensating differential, and indirectly, because of the value of the outside option, which plays a crucial role in the bargaining process.

\footnotetext{
${ }^{8}$ Usui's (2006) application to hours worked confirms their results. Lang and Majumdar (2004) obtain a similar result in a nonsequential search environment. Gronberg and Reed (1994) study the marginal willingness to pay for job attributes, estimating a partial equilibrium job search model on job durations. Their approach differs from ours because they do not use flexibility or hours worked among the job attributes and they do not attempt to fit the wage distribution.
} 
The impact of part-time or, more generally, of hours-wage trade-offs using hedonic wage models has been extensively studied. Moffitt (1984) is a classic example, providing estimates of a joint wage-hours labor supply model. Altonji and Paxson (1988) focus on a labor market with hours-wage contracts, concluding that workers need additional compensation to accept unattractive working hours. Blank (1990) estimates large wage penalties for working parttime, using CPS data, but suggests that selection into part-time is significant and that the estimates are not very robust.

There exist very few attempts at estimating models with frictions capable of recovering preferences. To our knowledge, none of these focus on estimating the value of job amenities. Blau (1991) estimates a search model in which utility depends both on earnings and on weekly hours worked. The main focus of this paper is on testing the reservation wage hypothesis. Bloemen (2008) estimates a search model with similar preferences to evaluate the difference between desired hours and actual hours worked. Blau's and Bloemen's approaches also differ from ours in that they assume firms posting joint wage-hours offers, while we allow individuals to bargain over wages and flexibility.

Methodologically, our paper relates to papers that estimate search and matching models with bargaining, which are a tractable version of partial-equilibrium job search models allowing for a wider range of equilibrium effects once major policy or structural changes are introduced. ${ }^{9}$ We extend the standard model in this class by including preferences for a job amenity. Dey and Flinn (2005) implemented a similar feature. They estimated preferences for health insurance. Our model differs from theirs because the provision of the job amenity is endogenously determined and can be used strategically within the bargaining process.

\section{The Model}

\subsection{Environment}

We consider a search model in continuous time with each job characterized by $(w, h)$ where $w$ is wage and $h$ is an additional amenity attached to the job. In the empirical implementation, $h$ is flexibility in hours worked. Workers have different preferences with respect to $h$ and firms pay a cost to provide it.

\footnotetext{
${ }^{9}$ See Eckstein and van den Berg (2007) for a survey. Models in this class have been used to study a variety of issues, such as duration to first job and returns to schooling (Eckstein and Wolpin 1995), race discrimination (Eckstein and Wolpin 1999), the impact of mandatory minimum wage (Flinn 2006), and gender discrimination (Flabbi 2010).
} 
Workers' instantaneous utility when employed is:

$$
u(w, h ; \alpha)=w+\alpha h ; h \in\{0,1\} ; \alpha \sim H(\alpha)
$$

where $\alpha$ defines the marginal willingness to pay for flexibility, the crucial preference parameter of the model, distributed in the population according to distribution $H$. The specification of the utility function is very restrictive, but we prefer to present the specification that we can empirically identify. More general specifications are possible, but the restriction that $w$ and $h$ enter additively in the utility function is difficult to remove if one needs to obtain a tractable equilibrium in a search environment.

Workers are either employed or unemployed. Workers' instantaneous utility when unemployed is defined by a utility (or disutility) level $b(\alpha)$. We allow for the possibility that individuals with different tastes for flexibility receive different utility for being unemployed.

Firms' instantaneous profits from a filled job are:

$$
\operatorname{Profits}(x, w, h ; k)=(1-k h) x-w ; k \in[0,1]
$$

where $x$ denotes the match-specific productivity and $k$ is the cost firms pay to provide flexibility. ${ }^{10}$ Cost $k$ may arise from the need to coordinate workers in the workplace and possibly the need to hire a higher number of workers when flexibility is provided, which generates additional search and training costs. Crucially, the total cost of flexibility $k x$ is proportional to potential productivity $x$. We believe this is a natural assumption given that the potential loss of productivity resulting from a lack of workers coordination is higher when workers are more productive, and training costs are higher when workers have higher skill levels.

Workers meet firms following a Poisson process with exogenous instantaneous arrival rate $\lambda .{ }^{11}$ Once a match is formed, the employer observes the worker's type ${ }^{12}$ (defined by $\alpha$ ) and a match-specific productivity $x$ is drawn from distribution $G: x \sim G(x)$. This is an additional source of heterogeneity, resulting from the match of a specific worker with a

\footnotetext{
${ }^{10} \mathrm{~A}$ standard equilibrium search model assumes a cost of posting a vacancy and then free-entry with endogenous meeting rates (usually determined by a matching function) to close the model. However, these costs are very difficult to identify using only workers data, so as a first approximation, we will assume firms spend nothing to post a vacancy.

${ }^{11}$ Keeping the arrival rate exogenous introduces a major limitation in the policy experiments because it ignores that firms can react by posting more or fewer vacancies. Data limitations prevent us from estimating a "matching function" in our application.

${ }^{12} \mathrm{It}$ is common in the literature to refer to the different values of $\alpha^{\prime} s$ as "types" of workers. In the same way we could define firms with different values of $k^{\prime} s$ as "types" of firms. In the current paper, we discuss and use in estimation the heterogeneity in workers' types but not in firms' types.
} 
specific employer.

Matched firms and workers engage in bargaining over a job offer defined by the pair $(w, h)$. The timing of the game is crucial for the bargaining game and for the search process. Before a match is formed, types are unknown. This implies that firms will not direct their search toward specific agents. This modeling assumption is needed to simplify the equilibrium characterization that would otherwise have to take into account the asymmetric information in the bargaining game.

A match is terminated according to a Poisson process with arrival rate $\eta$. There is no on-the-job search, and the instantaneous common discount rate is $\rho$.

\subsection{Value functions and the Bargaining Game}

This problem can be solved recursively to derive the value functions for employed and unemployed workers. ${ }^{13}$ The value of employment for a worker matched to a firm is:

$$
V_{E}(w, h ; \alpha, k)=\frac{w+\alpha h+\eta V_{U}(\alpha)}{\rho+\eta}
$$

The wage plus the benefit of flexibility $(w+\alpha h)$ is the instantaneous utility flow that an employed worker receives. Moreover, while employed, workers face the risk of job termination (with probability $\eta$ ), in which case they receive the value of the unemployment $V_{U}(\alpha)$. These values are appropriately discounted by the intertemporal discount rate $\rho$ and by the probability of job termination $\eta$.

The value of unemployment is:

$$
V_{U}(\alpha)=\frac{b(\alpha)+\lambda \int \max \left[V_{E}(w, h ; \alpha, k), V_{U}(\alpha)\right] d G(x)}{\rho+\lambda}
$$

The instantaneous flow of utility is denoted by $b(\alpha)$ and includes all the utility and disutility related to unemployment and job search, including unemployment benefits, if applicable. The second term of the numerator is an option value: While being unemployed and searching, the agent buys the option of meeting an employer, drawing a productivity value and deciding if the resulting job will generate a flow of utility higher than her current state of unemployment. The option value is the probability to meet the employer $(\lambda)$ multiplied by the expected value of the match, where the expectation is over the match-specific productivity distribution $(G(x))$. The expression takes into account that the worker accepts the match only if its value (resulting from the productivity draw) is greater than the value of

\footnotetext{
${ }^{13}$ The complete analytical derivation is presented in the Appendix A.1.
} 
unemployment. Again, both components are discounted by the intertemporal discount rate $\rho$ and by the probability to receive an employment offer $\lambda$.

For the firm, the value of a filled position is:

$$
V_{F}(x, w, h ; \alpha, k)=\frac{(1-k h) x-w}{\rho+\eta} .
$$

Equation (5) has an analogous interpretation of the worker's value function (3). In this case, the value of the alternative state, an unfilled vacancy, is zero because we assume that posting a vacancy costs nothing. ${ }^{14}$

Workers and firms bargain over the surplus. We assume that the outcome of the bargaining game is the pair $(w, h)$ described by the axiomatic Generalized Nash Bargaining Solution, using the value of unemployment and zero, respectively, as threat points, and $(\beta, 1-\beta)$ as the workers and the firm's bargaining power parameters. This allows us to characterize the bargaining outcome as the solution to a relatively simple problem. We first characterize the conditions under which firms and workers agree on a match. Then, we characterize whether a flexible or non-flexible job is formed, conditional on agents accepting the match.

To this end, we define the surplus $S$ of the match as the weighted product of the worker's and firm's net return from the match with weights $(\beta, 1-\beta)$ :

$$
\begin{aligned}
S(x, w, h ; \alpha, k) & \equiv\left[V_{E}(w, h ; \alpha, k)-V_{U}(\alpha)\right]^{\beta}\left[V_{F}(x, w, h ; \alpha, k)\right]^{(1-\beta)} \\
& =\frac{1}{\rho+\eta}\left[w+\alpha h-\rho V_{U}(\alpha)\right]^{\beta}[(1-k h) x-w]^{(1-\beta)}, 0 \leq \beta \leq 1 .
\end{aligned}
$$

The Generalized Nash Bargaining Solution is characterized as the pair $(w, h)$ that maximizes the surplus $S(x, w, h ; \alpha, k)$. To compute this solution, we first set the condition on the flexibility choice and then solve for the wage schedule. The solution is given by: ${ }^{15}$

$$
\begin{aligned}
\widetilde{w}(x, h) & =\arg \max _{w} S(x, w, h ; \alpha, k) \\
& =\beta(1-k h) x+(1-\beta)\left[\rho V_{U}(\alpha)-\alpha h\right] .
\end{aligned}
$$

For a better economic sense of this solution, we can rearrange terms as follows:

$$
\widetilde{w}(x, h)=\rho V_{U}(\alpha)-\alpha h+\beta\left(x+(\alpha-k x) h-\rho V_{U}(\alpha)\right) .
$$

\footnotetext{
${ }^{14}$ The same result can be obtained with the assumption of free-entry of firms in the market.

${ }^{15}$ To simplify notation, we did not include $\alpha$ as argument of $\widetilde{w}$ and the reservation values of $x$.
} 
We will show below that the first two elements in (9) $\left(\rho V_{U}(\alpha)-\alpha h\right)$ are equal to the reservation wage. The remaining terms correspond to the net surplus from the match multiplied by the worker's bargaining coefficient $\beta$.

The wage schedule, together with the previous value functions, implies that the optimal decision rule has a reservation value property. Because wages are increasing in $x$ (see (8)), the value of employment $V_{E}(w, h ; \alpha, k)$ is increasing in wages (Equation (3)) and the value of unemployment $V_{U}(\alpha)$ is constant with respect to wages (equation (4)). Then there exists a reservation value $x^{*}(h)$ such that the agent is indifferent between accepting and rejecting the match:

$$
V_{U}(\alpha)=V_{E}\left(\widetilde{w}\left(x^{*}(h), h\right), h ; \alpha, k\right) .
$$

Workers only accept matches with productivity higher than $x^{*}(h)$. An analogous decision rule holds for firms. Because of Nash bargaining, the reservation value at which the worker is indifferent between employment or unemployment is equal to the reservation value at which the firm is indifferent to the option of holding a vacancy or hiring the worker. Formally:

$$
V_{E}\left(\widetilde{w}\left(x^{*}(h), h\right), h ; \alpha, k\right)=V_{U}(\alpha) \Leftrightarrow V_{F}\left(x^{*}(h), \widetilde{w}\left(x^{*}(h), h\right), h ; \alpha, k\right)=0 .
$$

We use (10) to solve for $x^{*}(h)$, obtaining:

$$
x^{*}(h)=\frac{\rho V_{U}(\alpha)-\alpha h}{1-k h} .
$$

Substituting in (8), the corresponding reservation wage is:

$$
w^{*}(h)=\rho V_{U}(\alpha)-\alpha h
$$

Notice that if flexibility were not available (i.e., $h=0$ ), the reservation wage would be equal to the reservation value found in the search-matching-bargaining literature: $w^{*}(0)=$ $x^{*}(0)=\rho V_{U}(\alpha)$, that is, the discounted value of the outside option (the value of unemployment).

When flexibility is present, the optimal decision rule depends on $\alpha$ and $k$. Equation (12) states that providing flexibility has a direct impact in lowering the wage at which the worker is willing to accept a job. The impact is larger when the preference for flexibility is stronger. Equation (11) shows the relation between the flexibility provision and the productivity reservation value. It states that providing flexibility has two opposite effects on the reservation productivity value at which workers and firms will deem the match acceptable: Flexibility lowers the reservation value because the worker receives a valuable 
job amenity, but it also increases the reservation value because the firm pays a cost to provide the amenity.

We now characterize the choice of flexibility. Given a match-specific productivity value $x$, workers and firms compare the value of the job with flexibility and the value without flexibility. We define the productivity value that makes workers and firms indifferent to the flexibility of jobs as $x^{* * 16}$. Formally, $x^{* *}$ satisfies:

$$
\begin{aligned}
V_{E}\left(\widetilde{w}\left(x^{* *}, 1\right), 1 ; \alpha, k\right) & =V_{E}\left(\widetilde{w}\left(x^{* *}, 0\right), 0 ; \alpha, k\right) \\
& \Uparrow \\
V_{F}\left(x^{* *}, \widetilde{w}\left(x^{* *}, 1\right), 1 ; \alpha, k\right) & =V_{F}\left(x^{* *}, \widetilde{w}\left(x^{* *}, 0\right), 0 ; \alpha, k\right)
\end{aligned}
$$

In the optimal decision rule, the parties agree to form a flexible job if productivity is less than the threshold $x^{* *}$. Solving equation (13) we obtain:

$$
x^{* *}=\frac{\alpha}{k}
$$

On the one hand, because a higher utility from flexibility $\alpha$ increases the threshold $x^{* *}$, then individuals with higher $\alpha$ accept a job with flexibility over a larger support of $x$. On the other hand, for a firm with a high cost of providing flexibility, it will be optimal to offer a job with flexibility over a smaller support of $x$.

In the next subsection, we characterize the threshold productivities in terms of the values of the fundamental parameters. We exploit this characterization to define the equilibrium.

\subsection{Equilibrium}

We can characterize the optimal decision rule by comparing the values of the three reservation productivities defined in (11) and (14): $\left\{x^{*}(0), x^{*}(1), x^{* *}\right\}$. Recall that $x^{*}(0)$ is the reservation productivity value at which agents are indifferent to the options of unemployment and employment at a non-flexible job. $x^{*}(1)$ is the value at which agents are indifferent to unemployment and employment at a flexible job, and $x^{* *}$ is the value at which agents are indifferent to the option of employment at a flexible or at a non-flexible job. The following proposition characterizes the reservation values in terms of the model parameters: ${ }^{17}$

Proposition 1 For a given $k$, there exists a unique $\alpha^{*}$, defined as the solution to $\alpha^{*}=$

\footnotetext{
${ }^{16}$ Again, Nash bargaining guarantees that this threshold is the same for both worker and firm.

${ }^{17}$ The proof is in the Appendix A.2.
} 
$k \rho V_{U}\left(\alpha^{*}\right)$, such that:

$$
\begin{aligned}
& \alpha>\alpha^{*} \Longleftrightarrow x^{*}(1)<x^{*}(0)<x^{* *} \\
& \alpha=\alpha^{*} \Longleftrightarrow x^{*}(1)=x^{*}(0)=x^{* *} \\
& \alpha<\alpha^{*} \Longleftrightarrow x^{*}(1)>x^{*}(0)>x^{* *}
\end{aligned}
$$

Ignoring the cutting-edge case in which $\alpha=\alpha^{*}$, this proposition essentially defines two qualitatively different types of equilibria over two regions of the support of the distribution $H(\alpha)$.

Case 1: $\alpha>\alpha^{*}=k \rho V_{U}\left(\alpha^{*}\right)$.

Proposition 1 establishes that in this case we have $x^{*}(1)<x^{*}(0)<x^{* *}$. Therefore, the optimal decision rule in this region of the $\alpha$-parameter support is:

$$
\begin{array}{cl}
x<x^{*}(1) & \text { reject the match } \\
x^{*}(1)<x<x^{* *} & \text { accept the match }\{\widetilde{w}(x, 1), 1\} \\
x^{* *}<x & \text { accept the match }\{\widetilde{w}(x, 0), 0\}
\end{array}
$$

Figure 1 illustrates the value functions for the employment and unemployment states (equations (3) and (4)), as a function of the match-specific productivity $x$. Utility maximization implies that the optimal behavior is choosing the value function delivering the highest value for each $x$. The value of being unemployed, $V_{U}(\alpha)$, is the horizontal line that does not depend on wages and is therefore constant with respect to $x$. The value of being employed both in flexible and non-flexible jobs is increasing in wages, and therefore, by Equation (8), it is increasing in $x$. However, again by (8), workers in a non-flexible job receive more surplus from additional productivity than workers in a flexible job; therefore, $V_{E}(\widetilde{w}(x, 0), 0 ; \alpha, k)$ is steeper than $V_{E}(\widetilde{w}(x, 1), 1 ; \alpha, k)$. For the same reason, when the productivity is extremely low, workers in flexible jobs are better off because they receive the benefit of flexibility. Therefore equation $V_{E}(\widetilde{w}(x, 1), 1 ; \alpha, k)$ has a higher intercept than equation $V_{E}(\widetilde{w}(x, 0), 0 ; \alpha, k)$. This configuration is common to both Case 1 and Case 2 equilibria. The difference between Case 1 and Case 2 is the location of the intersection points.

Case 1 is described in the left panel of Figure 1. For low values of the match-specific productivity $x$, agents prefer to reject the match because the value of unemployment is higher. The point of indifference for switching state is reached at $x=x^{*}(1)$ where both agents are indifferent to the option of leaving the match or entering a match with a flexible 

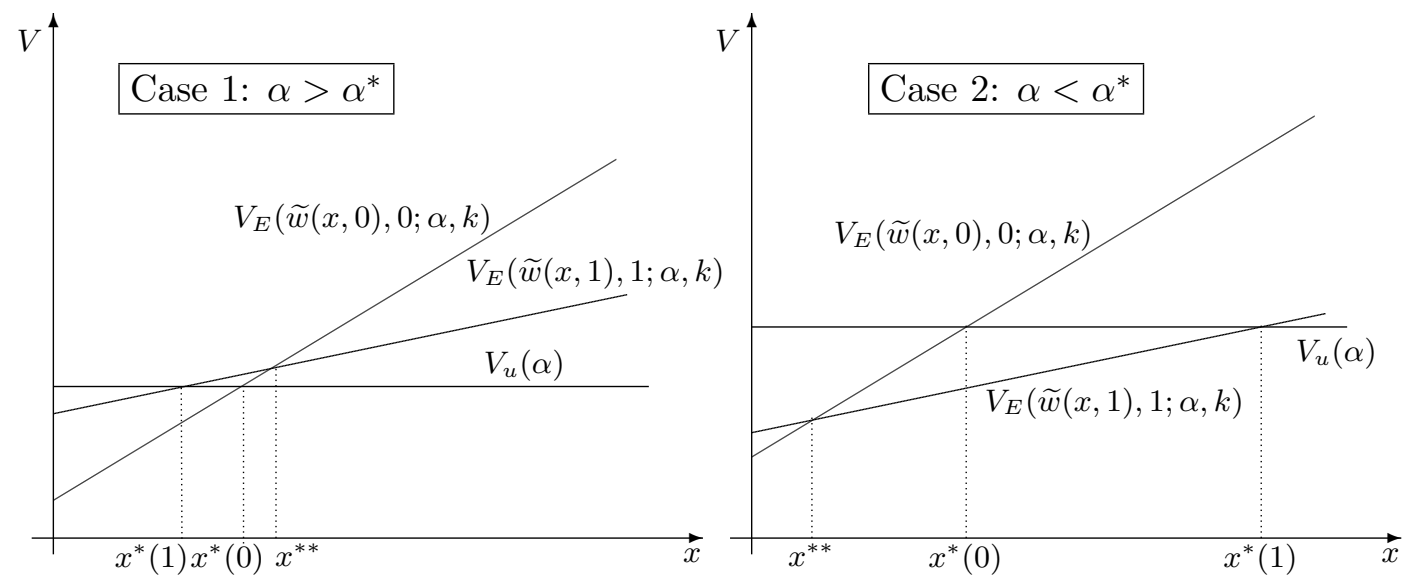

Figure 1: Different equilibrium outcomes

job and a wage determined by the match schedule (8). Between $x^{*}(1)$ and $x^{*}(0)$ only jobs with flexibility are acceptable because the value of a job without flexibility is lower than both the value of job with flexibility and the value of unemployment. Without the job amenity, jobs would be rejected in this range of productivity values. If $x \geq x^{*}(0)$, non-flexible jobs are acceptable, but if $x \leq x^{* *}$, the surplus a flexible job generates is higher than the surplus a non-flexible job generates, as shown by equation (13). Only for values of match-specific productivity higher than $x^{* *}$ the optimal decision rule is to accept a non-flexible job with a wage determined by (8). Finally, monotonicity of the difference (13) guarantees that this is the optimal decision rule for the rest of the support of $x$.

Given the optimal decision rules and conditioning on $\alpha$, the value of unemployment can be rewritten as:

$$
\begin{aligned}
\rho V_{U}(\alpha)= & b(\alpha)+\lambda \int_{x^{*}(1)}^{x^{* *}}\left[V_{E}(\widetilde{w}(x, 1), 1 ; \alpha, k)-V_{U}(\alpha)\right] d G(x) \\
& +\lambda \int_{x^{* *}}\left[V_{E}(\widetilde{w}(x, 0), 0 ; \alpha, k)-V_{U}(\alpha)\right] d G(x)
\end{aligned}
$$

which, after substituting the optimal wages schedules and value functions, becomes:

$$
\begin{aligned}
\rho V_{U}(\alpha)= & b(\alpha)+\frac{\lambda \beta}{\rho+\eta} \int_{\frac{\rho V_{U}(\alpha)-\alpha}{1-k}}^{\frac{\alpha}{k}}\left[x-\frac{\rho V_{U}(\alpha)-\alpha}{1-k}\right] d G(x) \\
& +\frac{\lambda \beta}{\rho+\eta} \int_{\frac{\alpha}{k}}\left[x-\rho V_{U}(\alpha)\right] d G(x)
\end{aligned}
$$


This equation (implicitly) defines the value of unemployment $V_{U}(\alpha)$ as a function of the primitive parameters of the model. Given that $G(x)$ is an increasing function, this equation has a unique solution.

Case 2: $\alpha<\alpha^{*}=k \rho V_{U}\left(\alpha^{*}\right)$.

By Proposition 1, in this case $x^{* *}<x^{*}(0)<x^{*}(1)$. Therefore, the optimal decision rule in this region of the $\alpha$-parameter support is:

$$
\begin{array}{ll}
x<x^{*}(0) & \text { reject the match } \\
x^{*}(0)<x & \text { accept the match }\{\widetilde{w}(x, 0), 0\}
\end{array}
$$

In Case 2, the added utility of flexibility relative to the cost of providing it is not enough to generate acceptable flexible jobs: only non-flexible jobs with high enough match-specific productivity are acceptable to both agents. This case is illustrated on the right panel of Figure 1. The indifference to the two employment options, $x^{* *}$, occurs in a region in which agents do not accept matches. Agents prefer employment to unemployment (or a filled job to a vacancy) only when the match-specific productivity is higher and the optimal choice is to accept jobs without flexibility.

Given the optimal decision rules and conditioning on $\alpha$, the value of unemployment can be rewritten as:

$$
\rho V_{U}(\alpha)=b(\alpha)+\lambda \int_{\rho V_{U}(\alpha)}\left[V_{E}(\widetilde{w}(x, 0), 0 ; \alpha, k)-V_{U}(\alpha)\right] d G(x)
$$

which, after substituting the optimal wages schedules and value functions, is equivalent to:

$$
\rho V_{U}(\alpha)=b(\alpha)+\frac{\lambda \beta}{\rho+\eta} \int_{\rho V_{U}(0)}\left[x-\rho V_{U}(\alpha)\right] d G(x)
$$

Similarly to (16), this equation implicitly and uniquely defines the value of unemployment $V_{U}(\alpha)$ as a function of the primitive parameters of the model.

The optimal behavior of Case 1 and Case 2 can be summarized as follows:

Definition 2 Given $\{\lambda, \eta, \rho, \beta, b(\alpha), k, G(x), H(\alpha)\}$ an equilibrium is a set of values $V_{U}(\alpha)$ that solves equation (16) for any $\alpha \leq \alpha^{*}$ and a set of $V_{U}(\alpha)$ that solves equation (18) for any $\alpha>\alpha^{*}$ in the support of $H(\alpha)$.

This definition states that, given the exogenous parameters of the model, we can solve for the value functions that uniquely identify the reservation values: the reservation values 
are the only piece of information we need to fully characterize the optimal behavior. The equilibrium exists and it is unique because equations (16) and (18) admit a unique solution. The proof involves showing that both equations define a contraction mapping: it is relatively straightforward in this case because we are integrating positive quantities on a continuous probability density function.

This definition is also very convenient from an empirical point of view because - as we will see in more detail in the identification section - we can directly estimate the reservation values and, from them, recover information about the value functions and the primitive parameters.

We now characterize the equilibrium unemployment rate. Given that the arrival rate of matches follows a Poisson process with parameter $\lambda$, it can be shown that in an infinite horizon model the hazard rate out of unemployment $r$ is constant over time: ${ }^{18},{ }^{19}$

$$
\begin{array}{ll}
r(\alpha)=\lambda\left(1-G\left(x^{*}(1)\right)\right. & \text { if } \alpha>\alpha^{*} \\
r(\alpha)=\lambda\left(1-G\left(x^{*}(0)\right)\right. & \text { if } \alpha \leq \alpha^{*}
\end{array}
$$

It can also be shown that the expected duration in unemployment is equal to the inverse of the hazard rate:

$$
\frac{1}{\int r(\alpha) d H(\alpha)}
$$

a result that we will exploit for identification purposes.

Finally, in steady state the flows of workers into employment status should be equal to the flow out of it. Hence, defining $U$ as the unemployment rate, it must be the case that $U \cdot \int r(\alpha) d H(\alpha)=\eta \cdot(1-U)$, or, equivalently,

$$
U=\frac{\eta}{\int r(\alpha) d H(\alpha)+\eta}
$$

which defines the unemployment rate in equilibrium.

We provide now some economic intuition related to the equilibrium characterization. Because the cost of providing flexibility is higher for highly productive matches, only relatively lower productivity matches will be associated with flexible jobs. In relatively highproductivity matches, the higher wage compensates the worker for not having a flexible job. This is a result of the bargaining process: Because workers share a proportion of the

\footnotetext{
${ }^{18}$ See, e.g., Flinn and Heckman (1982). The hazard rate out of unemployment $h$ is defined as the probability of leaving unemployment conditional on the worker having been unemployed for a given length of time.

${ }^{19}$ The hazard rates depend on $\alpha$ because the reservation productivity levels depend on $\alpha$. See Footnote 15.
} 
surplus generated by the match, there will always be a value of the rent high enough that more than compensates the utility gain of working in a flexible job. ${ }^{20}$ For similar reasons, if a worker has a significant utility from flexibility and the productivity is low enough, it will be optimal to give up some of the relatively small share of surplus to gain job flexibility. The range of productivities over which flexible jobs are accepted is directly related to preferences because a higher $\alpha$ means that the distance between the two reservation values $x^{* *}$ and $x^{*}(1)$ is larger. Section 4 describes the direct implication of this result on observed wages, which provides a useful relationship between the data and the model parameters that is exploited for the empirical identification.

Observe in the left panel of Figure 1 that the interval $\left[x^{*}(1), x^{*}(0)\right]$ identifies matches that would have not been created without the flexible job option. This interval illustrates an efficiency gain of having the option to offer flexible jobs. If the flexibility option were not available, fewer matches would be created, leaving more jobs unfilled and more workers unemployed.

\section{Identification}

The parameters to be identified are the bargaining power $\beta$, the parameters of the distribution over the match-specific productivities $G(x)$, the match arrival rate $\lambda$ and termination rate $\eta$, the discount rate $\rho$, the utility flow during unemployment $b$, the cost of providing flexibility $k$, and the distribution over preferences for flexibility $H(\alpha)$. We discuss identification based on data containing the following information: accepted wages, unemployment durations and an indicator of flexibility. We denote it with the set:

$$
\Delta \equiv\left\{w_{i}, t_{i}, h_{i}\right\}_{i=1}^{N}
$$

If the drawback of our approach is the reliance on some functional form assumptions for identification, one advantage is the relatively minor data requirement needed for the estimation.

The bargaining power parameter. The separate identification of this coefficient is difficult without demand side information; therefore, we resort to a common assumption in the literature, which is to assume symmetric bargaining, or $\beta=1 / 2{ }^{21}$

\footnotetext{
${ }^{20}$ To be precise, this is true if the sampling productivity distribution is not bounded as above. If there is an upper bound to productivity and the share at this upper bound is small enough, it is possible that some high $\alpha$-types will never work in a non-flexible job.

${ }^{21}$ See Flinn (2006) and Eckstein and Wolpin (1995).
} 
The "classic"search-matching model parameters. These are the parameters included in the set:

$$
\Theta(\alpha) \equiv\{\lambda, \eta, \rho, b(\alpha), G(x)\}
$$

conditioning on a given type $\alpha$. Our discussion can then be replicated for each type as long as the types are identified.

The proof of identification of $\Theta(\alpha)$ from the vector of data $\Delta$ was first proposed by Flinn and Heckman (1982). First, they established that the only features of the model that can be identified nonparametrically are the reservation wage (identified by the minimum observed wage) and the hazard rate out of unemployment (identified by the inverse of the average duration in unemployment). As a result, a distributional assumption on the match distribution $G(x)$ is necessary to identify the structural parameters in the set $\Theta(\alpha)$.

Second, they proved that the distributional assumption must be such that $G(x)$ is recoverable. ${ }^{22}$ This condition arises because they observe only the accepted wage distribution but they want to identify the offered wage distribution. In our case, we want to identify the sampling distribution of match-specific productivity, using the accepted wage distribution. Therefore, our model requires the same parametric assumption because the sampling distribution maps into wage offers through the optimal Nash bargaining solution. We can therefore identify the wage offers distribution from the accepted wage distribution, thanks to the recoverability condition. Then, we can identify the productivity distribution $G(x)$ by inverting the mapping wage-productivity implied by Nash bargaining.

Third, once the reservation values, the hazard rate out of unemployment and the sampling distribution $G(x)$ are identified, equations (19) and (20) identify $\lambda$ and equation (22) plus knowledge of the unemployment rate identify $\eta$.

Finally, the parameters $\rho$ and $b(\alpha)$ can only be jointly identified. This is the case because they contribute to the mapping from the data to the parameters only through the discounted value of unemployment $\rho V_{U}(\alpha)$. This value is not a primitive parameter but an implicit function of various parameters (see equations (16) and (18)). ${ }^{23}$ If $\rho V_{U}(\alpha)$ is identified, then $\rho$ and $b(\alpha)$ can be jointly recovered using the equilibrium equation that implicitly defines $\rho V_{U}(\alpha)$.

\footnotetext{
${ }^{22}$ A distribution $G$ is recoverable from a truncated distribution with known truncation point $z$ if knowledge of $G(x \mid x \geq z)$ and $z$ implies that $G$ is uniquely determined. Examples of recoverable distributions include the Normal and the Log-normal.

${ }^{23}$ Postel-Vinay and Robin (2002) have one of the few articles providing direct estimates of the discount rate within a search framework. Their model is, however, not comparable to ours because the discount rate includes both "impatience" (as in our model) and risk aversion. They generate high estimates for this parameter: about $12 \%$ for the skilled group and up to $65 \%$ for some unskilled groups in some specific industries.
} 
Cost to provide and preferences for flexibility. This is set of parameters that is specific to our model and not commonly found in the literature: the distribution of preferences for flexibility $\alpha$ and the cost of providing flexibility $k$.

Heterogeneity in preferences for flexibility helps us fit the data we observe. For example, if there were only one type of worker with $0 \leq \alpha<k \rho V_{U}(0)$, then in equilibrium we would observe only non-flexible jobs. If instead there were only one type with $k \rho V_{U}(\alpha) \leq \alpha$, then we could observe workers in both types of jobs. However, the wage distributions of the two jobs would have non-overlapping support, something we do not observe in the data. Multiple types generate an accepted wage distribution as a mixture of distributions (one for each type) that is capable of better fitting the data we observed for flexible and non-flexible jobs.

More formally, we follow what is now a standard approach in the literature and assume a discrete distribution $H(\alpha)$, implying a finite number of values $\alpha_{j}, J=0 \ldots T .{ }^{24}$ We then call $p_{j}, j=0 \ldots T$ the proportion of individuals with a preference for flexibility $\alpha_{j}$ (or, more concisely, the frequency of individuals of type $j$ ). The set of parameters left to be identified is therefore:

$$
\Upsilon \equiv\{\alpha, \mathbf{p}, T, k\}
$$

where $\alpha$ and $\mathbf{p}$ are vectors of dimension $T+1$.

We proceed by steps, first focusing on the identification of $\alpha, \mathbf{p}$ and $k$ given the number of types and assuming we know how to group individuals by type. Then we expand our analysis to the case in which we do not observe workers' types.

When types are observed, identification of $\mathbf{p}$ is trivial, and it is given by the proportion of workers that belong to each type. The identification of the other parameters is more complex, and it depends on the categorization of equilibrium types illustrated in the previous section. For $\alpha_{j}$ such that $\alpha_{j}>k \rho V_{U}\left(\alpha_{j}\right)$ (equilibrium Case 1), the accepted wage distributions of flexible and non-flexible jobs do not have a connected support. ${ }^{25}$ This is because the marginal worker that does not accept a flexible job, the worker with productivity $x^{* *}$, receives a compensating differential for the lack of flexibility: $\widetilde{w}\left(x^{* *}, 1\right)=\widetilde{w}\left(x^{* *}, 0\right)-\alpha$. The productivity thresholds therefore define bounds in the support of the wage distributions we

\footnotetext{
${ }^{24}$ See, e.g., Wolpin (1990), Eckstein and Wolpin (1995) or Eckstein and van den Berg (2007)).

${ }^{25}$ Throughout the identification discussion and in the empirical application, we assume the support of $G(x)$ is equal to the positive real line. This seems a fairly reasonable assumption because $x$ represents the productivity of a job match.
} 
can use to identify some structural parameters. From equations (8), (11) and (14) we have:

$$
\begin{aligned}
\widetilde{w}\left(x^{*}(1), 1\right) & =\rho V_{U}\left(\alpha_{j}\right)-\alpha_{j} \\
\widetilde{w}\left(x^{* *}, 1\right) & =\beta(1-k) \frac{\alpha_{j}}{k}+(1-\beta)\left[\rho V_{U}\left(\alpha_{j}\right)-\alpha_{j}\right] \\
\widetilde{w}\left(x^{* *}, 0\right) & =\beta \frac{\alpha_{j}}{k}+(1-\beta) \rho V_{U}\left(\alpha_{j}\right)
\end{aligned}
$$

Solving this system of equations, we obtain:

$$
\begin{aligned}
\widehat{\alpha_{j}} & =\widetilde{w}\left(x^{* *}, 1 ; \alpha_{j}\right)-\widetilde{w}\left(x^{* *}, 0\right) \\
\rho \widehat{V_{U}\left(\alpha_{j}\right)} & =\widehat{\alpha_{j}}+\widetilde{w}\left(x^{*}(1), 1\right) \\
\widehat{k} & \left.=\beta \widehat{\alpha_{j}}\left[\widetilde{w}\left(x^{* *}, 0\right)-(1-\beta) \rho \widehat{V_{U}\left(\alpha_{j}\right.}\right)\right]^{-1}
\end{aligned}
$$

These three equations state that the size of the discontinuity in the wage support identifies the preference for flexibility, which is the compensating wage differential for the marginal worker accepting a non-flexible job. The minimum wage in the sample of observations belonging to type $\alpha_{j}$ identifies the discounted value of unemployment. The location of the discontinuity identifies $k$. The same intuition holds for any $\alpha_{j}$ such $\alpha_{j}>k \rho V_{U}\left(\alpha_{j}\right)$; therefore, the model is over-identified because there is only one flexibility cost $\widehat{k}$.

For any $\alpha_{j}$ such $\alpha_{j}<k \rho V_{U}\left(\alpha_{j}\right)$ (equilibrium Case 2 in the previous section), all of the accepted jobs are non-flexible and flexibility has no impact on the variables that we can observe. Therefore, we cannot identify $\alpha_{j}$ in this case. We denote all types $\alpha_{j}^{\prime}$ such that this is the case with $\alpha_{0}$ and normalize $\alpha_{0}$ to zero. This should not have a major impact in our results and counterfactuals because in the estimation, we obtain values of $\alpha_{j}>k \rho V_{U}\left(\alpha_{j}\right)$ that are quite low (between 0.1 and 0.01 ), and $\alpha_{0}$ must be smaller than the smallest estimated $\alpha_{j}>k \rho V_{U}\left(\alpha_{j}\right)$.

We now focus on the identification of $\alpha, \mathbf{p}$ and $k$, given $T$ without assuming we know the workers' types. In this case, the observed wage distribution is a mixture of wage distributions over the $T+1$ types and we want to identify the proportions in the mixture (p) together with the values of the $\left(\alpha_{\mathbf{j}}\right.$ 's). Because the discontinuity in the accepted wage support for one type may overlap with a region without discontinuity for another type, the mixture may not exhibit the discontinuity we used for identification in the previous case. However, the mixture will still exhibit a drop in probability mass in correspondence with the discontinuity in the accepted wage distribution for a given type. This is because in this region that type does not place any probability mass. As a result, the presence of a drop in the accepted wage distribution signals the presence of an $\alpha_{j}$-type such that $\alpha_{j}>k \rho V_{U}\left(\alpha_{j}\right)$. 
From equation (26), we also know that the width of the support over which the drop occurs identifies the size of the $\alpha_{j}$. The height of the drop identifies the proportion $p_{j}$ : the stronger the drop the higher the proportion of that specific type in the population. The location of the drops with respect to the lowest accepted wage identifies $k$ because $k$ is proportional to the distance $\left[\widetilde{w}\left(x^{* *}, 0\right)-\widetilde{w}\left(x^{*}(1)\right)\right]$, as shown in equation (28). The density of the wage distribution exhibits drops, and the presence of different types with different $\alpha_{j}^{\prime} s$ smooths out the kinks. The degree of smoothness depends both on the total number of types present and on the relative proportion of the types in the population.

Finally, the number of types $T$, with $\alpha_{j}$ such that $\alpha_{j}>k \rho V_{U}\left(\alpha_{j}\right)$ is identified by the number of discontinuities in the support of the accepted wage distribution and/or by the number of drops in the density of the accepted wage distribution.

\section{Data}

For identification purposes, we need a data set reporting accepted wages, unemployment durations, a flexibility indicator, and some information regarding age and schooling to select a relatively homogenous estimation sample.

Finding a good flexibility indicator is a difficult task: ideally, we would like to have a variable indicating if the worker can freely choose how to allocate her working hours. In principle, this type of information is observable (e.g., some labor contracts have a flextime option, allowing workers to enter and exit the job at her chosen time or allowing workers to bundle extra working hours to gain some days off). However, there is lack of an homogenous definition across firms and industries of these types of contract. For this reason, we use a limited but transparent and comparable definition of flexibility that allows us to use a standard and representative sample of the U.S. labor market. The definition of flexibility we use is based on hours worked under the assumption that working fewer hours per week is a way to obtain the type of flexibility we are interested in. For comparability across workers with different flexibility choices, we measure wages in dollars per hour.

The data is extracted from the Annual Social and Economic Supplement (ASES or March supplement) of the CPS for the year 2005. We consider only women who declare themselves as white, who are in the age range 30-55 years old, and who belong to two educational levels: those who completed high school (high school sample) and those who completed college at least (college sample). To avoid outliers and top-coding issues, we trim hourly earnings, excluding the top and the bottom $1 \%$ of the raw data.

The variables that we extract are on-going unemployment durations observed for individ- 


\begin{tabular}{lcc} 
Females & College & High School \\
\hline N. flexible & 264 & 240 \\
N. non-flexible & 1058 & 854 \\
Average wage, flexible & $22.5(14.2)$ & $10.3(4.3)$ \\
Average wage, non-flexible & $23.4(10.3)$ & $13.9(5.9)$ \\
Wage range, flexible & $2.4-70$ & $2.13-26.7$ \\
Wage range, non-flexible & $7-57.7$ & $3.65-38.5$ \\
Avg. hours worked, flexible & $21.3(7.7)$ & $23.4(7.6)$ \\
Avg. hours worked, non-flexible & $42.7(6.4)$ & $40.5(3.8)$ \\
N. unemployed & 34 & 72 \\
Avg. unemployment duration & $4.4(5.2)$ & $4.6(5.9)$
\end{tabular}

Table 1: Descriptive statistics (standard deviations in parenthesis)

uals currently unemployed $\left(t_{i}\right)$; accepted wages observed for individuals currently employed $\left(w_{i}\right)$ and the flexibility regime $\left(h_{i}\right)$ in which the worker is assumed to be in a flexible job if she is working less than 35 hours per week. We obtain a sample for which descriptive statistics are presented in Table 1. Accepted earnings are measured in dollars per hour and unemployment durations in months.

\section{Estimation}

The minimum observed wage is a strongly consistent estimator of the reservation wage ${ }^{26}$. In our model, we can exploit this property of observed minimum wages in both flexible and non-flexible jobs because it refers to the reservation wage of two different types of individuals: the lowest accepted wage at non-flexible jobs is a strongly consistent estimator for the reservation wage of workers' type such that $\alpha<k \rho V_{U}(\alpha)$, while the lowest accepted wage at flexible jobs is a strongly consistent estimator for the reservation wage of workers who belong to one of the types satisfying $\alpha>k \rho V_{U}(\alpha)$. Without loss of generality, we assume this: the lowest accepted wage of a flexible job pertains to type $\mathrm{T}$.

To summarize, the first step of our estimation procedure uses equation (12) to obtain the following strongly consistent estimators:

$$
\begin{aligned}
\widehat{\rho V_{U}(0)} & =\min _{i}\left\{w_{i}: h_{i}=0\right\} \\
\rho V_{U} \widehat{\left(\alpha_{T}\right)}-\alpha_{T} & =\min _{i}\left\{w_{i}: h_{i}=1\right\}
\end{aligned}
$$

\footnotetext{
${ }^{26}$ See Flinn and Heckman (1982)
} 
We estimate the remaining parameters in a second step using a Simulated Method of Moments (SMM) procedure in which, for a given parameters vector, we simulate moments that we compare with the corresponding moments obtained from the data sample. ${ }^{27}$

We estimate $\lambda$ and $\eta$ by matching two moments exactly: the mean duration of unemployment spells as equal to the hazard rate (see (21)), which, together with the unemployment rate $(22)$, defines a system of two linear equations in two unknowns $(\lambda$ and $\eta)$.

Assuming $G(x)$ is lognormal with parameters $(\mu, \sigma),{ }^{28}$ the remaining vector of parameters is defined by $\theta \equiv\left\{\mu, \sigma, k, \alpha, \mathbf{p}, \rho V_{U}\left(\alpha_{-j}\right)\right\}$ and is estimated as:

$$
\begin{aligned}
\widehat{\theta}= & \arg \min _{\theta} \Psi(\theta, \mathbf{t}, \mathbf{w}, \mathbf{h})^{\prime} W \Psi(\theta, \mathbf{t}, \mathbf{w}, \mathbf{h}) \\
& \text { such that } \Psi(\theta, \mathbf{t}, \mathbf{w}, \mathbf{h})=\left[\Gamma_{R}\left(\theta \mid \widehat{\rho V_{U}(0)} ; \rho V_{U} \widehat{\left(\alpha_{j}\right)}-\alpha_{j}\right)-\gamma_{N}(\mathbf{t}, \mathbf{w}, \mathbf{h})\right]
\end{aligned}
$$

where $\gamma_{N}$ is the vector of the sample moments obtained by our sample of dimension $N$, and $\Gamma_{R}\left(\theta \mid \rho \widehat{V_{U}(0)} ; \rho V_{U} \widehat{\left(\alpha_{j}\right)}-\alpha_{j}\right)$ is the vector of the corresponding moments obtained from a simulated sample of size $R$ conditional on the estimated values of $\widehat{\rho V_{U}(0)}$ and $\rho V_{U} \widehat{\left(\alpha_{j}\right)}-\alpha_{j}$. Bold type represents vectors of variables: for example $\mathbf{t}$ is the vector of the unemployment durations $t_{i}$. The weighting matrix $W$ is a diagonal matrix with elements equal to the inverse of the bootstrapped variances of the sample moments.

The moments we match are extracted from the unemployment durations and from the accepted wages distributions at flexible and non-flexible jobs. For the unemployment durations, we simply compute the mean and the proportion of individuals in unemployment. For the wage distributions, we exploit that with multiple types of workers, workers with flexible and non-flexible jobs have accepted wage distributions with overlapping support. We attain that by computing means and standard deviations of wages at flexible and nonflexible jobs over various percentile ranges defined by accepted wages at non-flexible jobs. In addition, we need to use enough moments of the wage distribution in order to capture the "drops" that correspond to the discontinuous support of the wage distributions of a given type. We use percentiles 0, 20, 40, 60, 80 and 100 of the non-flexible workers' accepted wage distribution to define 5 intervals. Within these 5 intervals, we compute the proportion of workers holding flexible jobs and the mean and standard deviations of wages with flexible

\footnotetext{
${ }^{27}$ In principle, one could attempt a maximum likelihood approach. This is difficult in our model because each type $\alpha$ such that $\alpha>k \rho V_{U}(\alpha)$ defines a parameter-dependent support over flexible and non-flexible jobs and the first step allows the estimation of only one such type $\alpha$. The support of the variables over which the likelihood is defined depends on parameters and, therefore, a standard regularity condition is violated.

${ }^{28}$ This is the most commonly assumed distribution in this literature because it satisfies the recoverability condition for the identification of its parameters and it provides a good fit for observed wages distributions.
} 


\begin{tabular}{lcc} 
Parameter & College & High School \\
\hline \hline$\mu$ & $3.5343(0.0066)$ & $3.0107(0.0116)$ \\
$\sigma$ & $0.5378(0.0056)$ & $0.4841(0.0075)$ \\
$\eta$ & $0.0057(0.0016)$ & $0.0136(0.0026)$ \\
$\lambda$ & $0.2288(0.0504)$ & $0.2196(0.0355)$ \\
\hline$\alpha_{1}$ & $0.1035(0.0609)$ & $0.0100(0.00004)$ \\
$p_{1}$ & $0.1256(0.0103)$ & $0.2084(0.0337)$ \\
$\alpha_{2}$ & $0.0100(0.00003)$ & $0.0255(0.0120)$ \\
$p_{2}$ & $0.2437(0.0119)$ & $0.1641(0.0202)$ \\
$k$ & $0.0004(0.00004)$ & $0.0006(0.00005)$ \\
\hline$\rho V_{U}(0)$ & $7.0000(0.0211)$ & $3.6500(0.2449)$ \\
$\rho V_{U}\left(\alpha_{1}\right)$ & $15.3092(5.1034)$ & $3.9059(0.8017)$ \\
$\rho V_{U}\left(\alpha_{2}\right)$ & $2.4100(1.1328)$ & $2.1555(0.1250)$ \\
\hline Loss function & 46.561 & 3.671 \\
$\mathrm{~N}$ & 1,356 & 1,166
\end{tabular}

Table 2: Estimation results (bootstrapped standard errors from 140 samples in parenthesis)

and non-flexible jobs. ${ }^{29}$

\section{Results}

The model is estimated separately from data regarding women with a high school degree and regarding women with at least a college degree. The implicit assumption is that the labor market is segmented along observable workers' characteristics so that the two education groups do not compete for the same jobs. This assumption is consistent with the ex-ante homogeneity condition imposed in the theoretical model and with previous literature on the estimation of search models. ${ }^{30}$

The specification of the unobserved heterogeneity in preferences for flexibility includes three types. Due to the non-identification result discussed in Section 4, for the Case-2 equilibria with $\alpha_{j}<k \rho V_{U}\left(\alpha_{j}\right)$ (such that workers only accept non-flexible jobs) we set $\alpha_{0}=0$. We estimated the model with four types, but the specification did not generate a significant improvement of the model fit. ${ }^{31}$

Estimated parameters are reported in Table 2. The parameter estimates fit the data well (see the table in the the Appendix A.3) and therefore provide a reasonable base for the

\footnotetext{
${ }^{29}$ The complete list of the simulated moments is in the Appendix A.3.

${ }^{30}$ See, for example, Bowlus (1997) and Eckstein and Wolpin (1995).

${ }^{31}$ The value of $\alpha$ estimated for the additional type converged to the value of $\alpha$ of one of the existing types, and the proportion of workers associated to the additional type in the population was negligible.
} 
counterfactuals we conduct in the next section. Observe first that arrival rates, termination rates, and the two parameters of the lognormal distribution of match-specific productivity are comparable to the corresponding values obtained in the literature. ${ }^{32}$ The arrival rates imply that agents receive an offer, which they may accept or reject, about every 4 months on average. The sampling productivity distribution parameters $(\mu, \sigma)$ imply that the average productivity of college graduates is almost $\$ 40$ per hour while the average productivity of high school graduates is about $\$ 23$ per hour. The reservation wages should be interpreted as measured in dollars per hour, and they appear to be within a reasonable range.

The flexibility-related parameters have plausible values: about $37 \%$ of college educated women are willing to pay between 1 and 10 cents per hour to work in flexible jobs. Firms' cost of providing flexibility is $0.04 \%$ of the hourly potential productivity. A similar proportion of women with a high school education value flexibility, but they are willing to pay a lower dollar amount (between 1 and 2.5 cents per hour), while firms face a higher cost of providing it, about $0.06 \%$ of the hourly potential productivity.

We have a very limited model of the firms side of the market, so it is difficult to find an explanation about why firms employing low-skilled workers may have higher cost of flexibility. Although firms needing only workers with lower skills makes it easier to substitute workers, secretarial and manual jobs are often performed in teams and may require a higher need for coordinating work-hours among workers than professional jobs.

The difference between the parameter estimates on high-school and college graduates suggests that women might choose schooling in part to accommodate a preference for job flexibility. Schooling is costly, but it provides access to jobs with relative low cost of flexibility. This might provide a partial explanation to the puzzle of why women have lower wages than men but acquire more schooling. ${ }^{33}$

\section{Counterfactual Policy Experiments}

We present two counterfactual experiments to assess the importance of flexibility. To compute the equilibrium and derive welfare implications under each experiment's assumptions we need, in addition to the estimates presented in the previous section, estimates of the flow

\footnotetext{
${ }^{32}$ See, for example, Flabbi (2010) and Bowlus (1997), who estimated comparable search models on samples of women. Flabbi used CPS 1995 data on white college graduates finding a very similar arrival rate and slightly lower average productivity in the presence of employers' discrimination. Bowlus used a National Longitudinal Survey of the Youth 1979 sample of college and high school women, finding a slightly lower hazard rate of unemployment in the presence of a non-participation state.

${ }^{33}$ The main explanations proposed so far have focused on the positive returns in the marriage market, see Chiappori, Iyigun and Weiss (2006) and Ge (2008).
} 
values of unemployment $b\left(\alpha_{j}\right)$. Because $\rho$ and $b\left(\alpha_{j}\right)$ are only jointly identified, we adopt a common assumption in the literature and fix the discount rate $\rho=0.05$ and recover $b\left(\alpha_{j}\right)$ using the equilibrium equations (16) (for $j=1,2$ ) and (18) (for $j=0$ ). ${ }^{34}$

To summarize, we base the experiments on the following set of structural parameters:

$$
\{\widehat{\mu}, \widehat{\sigma}, \widehat{\eta}, \widehat{\lambda}, \widehat{\alpha}, \widehat{\mathbf{p}}, \widehat{k}, \widehat{\mathbf{b}(\alpha)}\}
$$

We compute the equilibrium under the assumptions of each experiment, and we use it to generate simulated samples of 100,000 labor market careers. From the samples we compute various labor market statistics which we compare to a sample derived from the parameter estimates (which we refer to as the benchmark model). Table 3 presents these statistics for the benchmark model. Tables 4 and 5 compare the same statistics, obtained under the assumptions of each experiment, with those from benchmark model. The first row in each of these tables shows the discounted value of unemployment $\rho V_{U}(\alpha)$, which can be interpreted as a measure of welfare because $V_{U}(\alpha)$ is the present discounted value of participating in the labor market for a potential worker of type $\alpha$. The next set of rows report statistics about workers in non-flexible and (when present) flexible jobs: the average and standard deviation of accepted wages and the percentage of employed individuals of a given type working in each flexibility regime. The next two rows present the average unemployment duration and the unemployment rate. The last set of rows display firms' per-worker and total profits from flexible and non-flexible jobs. ${ }^{35}$

\subsection{Counterfactual 1: No flexibility}

To understand the impact of flexibility, we ask how much the labor market outcomes of women would change if flexibility were not available. To answer this question, the first policy experiments imposes that all jobs must be non-flexible. All parameters are set at their estimated values.

In this new environment, the only decision workers have to make is between accepting or rejecting a wage offer at a non-flexible job. Therefore, the optimal decision rule is characterized by only one reservation value for each type of worker, which we obtain by equating the value of unemployment and the value of employment at a given wage. This

\footnotetext{
${ }^{34}$ Flinn and Heckman (1982) use a value of $5 \%$ and $10 \%$, and Flinn (2006) uses 5\%. We performed sensitivity analysis and found that doubling discount rate to $10 \%$ does not make an appreciable difference on the results.

${ }^{35}$ The values in the "All" column are not simple averages of each group's mean but averages computed on the overall relevant sample.
} 


\begin{tabular}{lcccc|ccccc} 
& \multicolumn{9}{c}{ College } \\
& $\alpha_{0}$ & $\alpha_{1}$ & $\alpha_{2}$ & All & $\alpha_{0}$ & $\alpha_{1}$ & $\alpha_{2}$ & All \\
\hline$\rho V_{U}(\alpha)$ & 7.000 & 15.309 & 2.410 & 6.925 & 3.650 & 3.906 & 2.156 & 3.458 \\
& & \multicolumn{7}{c}{ Workers in non-flexible jobs } \\
Mean wage & 23.335 & 172.338 & 25.433 & 23.803 & 13.242 & 16.008 & 27.685 & 13.932 \\
St. dev. wages & 11.367 & 29.763 & 10.998 & 11.462 & 5.833 & 5.499 & 6.273 & 6.097 \\
\% of workers & 100.00 & 0.007 & 69.971 & 80.125 & 100.00 & 66.236 & 6.432 & 77.608 \\
& & \multicolumn{7}{c}{ Workers in flexible jobs } \\
Mean wage &. & 28.392 & 10.730 & 21.880 &. & 8.118 & 11.448 & 10.401 \\
St. dev. wages &. & 11.246 & 2.279 & 12.424 &. & 1.412 & 4.190 & 3.880 \\
\% of workers & 0 & 99.993 & 30.029 & 19.875 & 0 & 33.764 & 93.568 & 22.392 \\
& & \multicolumn{7}{c}{ Unemployed workers } \\
Avg. unempl. dur. & 4.378 & 4.677 & 4.371 & 4.414 & 4.556 & 4.556 & 4.555 & 4.556 \\
Unempl. rate & 0.024 & 0.026 & 0.024 & 0.024 & 0.058 & 0.058 & 0.058 & 0.058 \\
& & \multicolumn{7}{c}{ Firms' profits } \\
Average (non-flexible) & 16.335 & 157.028 & 23.023 & 17.778 & 9.592 & 12.102 & 25.530 & 10.257 \\
Average (flexible) &. & 13.187 & 8.330 & 11.395 &. & 4.222 & 9.318 & 7.716
\end{tabular}

Table 3: Benchmark model, computed using the parameter estimates. "." refers to missing observations.

equilibrium equation - the equivalent of equation (11) in the pre-policy environment - is:

$$
x^{*}(0)=\rho V_{U}\left(\alpha_{j}\right)
$$

The new equilibrium is then defined by a set of $V_{U}\left(\alpha_{j}\right)$ that solve the equation:

$$
\rho V_{U}\left(\alpha_{j}\right)=b\left(\alpha_{j}\right)+\frac{\lambda \beta}{\rho+\eta} \int_{\rho V_{U}\left(\alpha_{j}\right)}\left[x-\rho V_{U}\left(\alpha_{j}\right)\right] d G(x \mid \mu, \sigma)
$$

which corresponds to equation (18) in the benchmark model.

This experiment has two unambiguous implications in terms of labor market outcomes. First, agents with preferences for flexibility have a lower value of participating in the labor market because a job amenity that they value is not available. We can measure this impact by comparing the present discounted value of unemployment $V_{U}\left(\alpha_{j}\right)$ with or without the policy. Second, the range of productivities that correspond to acceptable job matches is smaller than in the benchmark model. This can be understood by looking at the left panel in Figure 1. The range between $x^{*}(1)$ and $x^{*}(0)$ defines productivities where only flexible 


\begin{tabular}{|c|c|c|c|c|c|c|c|c|}
\hline & \multicolumn{4}{|c|}{ College } & \multicolumn{4}{|c|}{ High School } \\
\hline & $\alpha_{0}$ & $\alpha_{1}$ & $\alpha_{2}$ & All & $\alpha_{0}$ & $\alpha_{1}$ & $\alpha_{2}$ & All \\
\hline \multirow[t]{2}{*}{$\rho V_{U}(\alpha)$} & $=$ & 99.58 & 99.92 & 99.88 & $=$ & 99.96 & 99.33 & 99.92 \\
\hline & \multicolumn{8}{|c|}{ Workers in non-flexible jobs } \\
\hline Mean wage & $=$ & 16.43 & 82.39 & 98.22 & $=$ & 83.79 & 44.99 & 94.38 \\
\hline St. dev. wages & $=$ & 38.05 & 104.54 & 101.10 & $=$ & 107.16 & 93.07 & 96.03 \\
\hline \multirow[t]{2}{*}{$\%$ of workers } & $=$ & 1412473.1 & 142.91 & 124.80 & $=$ & 150.97 & 1554.80 & 128.85 \\
\hline & \multicolumn{8}{|c|}{ Unemployed workers } \\
\hline Avg. unempl. dur. & $=$ & 100.06 & 100.00001 & 100.01 & $=$ & 100.0004 & 100.00001 & 100.0001 \\
\hline \multirow[t]{2}{*}{ Unempl. rate } & $=$ & 100.05 & 100.00001 & 100.01 & $=$ & 100.0004 & 100.00001 & 100.0001 \\
\hline & \multicolumn{8}{|c|}{ Firms' profits } \\
\hline Per worker & $=$ & 8.32 & 80.55 & 92.60 & $=$ & 78.58 & 40.40 & 94.50 \\
\hline Total & $=$ & 9258.14 & 115.10 & 115.54 & $=$ & 118.60 & 622.49 & 121.76 \\
\hline
\end{tabular}

Table 4: Counterfactual 1, No flexibility. Benchmark model $=100, "="$ refers to no change

jobs are accepted. If we remove this job option, a portion of jobs in this range will remain unfilled.

Both of these impacts are very modest: Table 4 shows the decrease in $V_{U}\left(\alpha_{j}\right)$ is present for all the types that value flexibility, but the amount of the decrease is between 0.04 and 0.42 percent. The impact on the unemployment rate and unemployment duration is even smaller: they both increase after the policy for all the types that value flexibility, but the increase is between 0.06 percent and less than a thousandth of a percentage point.

The impacts are small for two reasons. First, the estimates of the utility value attached to flexibility is relatively modest and therefore dropping this amenity is not a big cost. The second reason is less trivial. In our model, workers accepting flexible jobs optimally react to the new environment by taking non-flexible jobs instead of becoming unemployed, which allows them to offset the impact on total welfare.

The implications for the distribution of accepted wages are ambiguous. First, accepted wages of agents with positive $\alpha$ change in two opposite directions. There is a positive effect because all of the jobs are non-flexible. There is no wage cut due to the provision of flexibility. There is a negative effect because the workers' outside option in bargaining with the firms, $V_{U}\left(\alpha_{j}\right)$, is lower. The outside option is lower because the labor market does not provide an amenity that the workers value. Second, the composition of the productivity distribution of the accepted non-flexible jobs is different: The accepted non-flexible jobs are on average less productive than the accepted non-flexible jobs in the pre-policy regime because in the pre-policy regime, low productivity matches were associated with flexible 
jobs.

The results show that the negative effects dominate. The average wages for types that value flexibility is considerably smaller, ranging from $16.4 \%$ of the average wage in the benchmark model for the $\alpha_{1}$-type in the college sample to $83.8 \%$ for the $\alpha_{1}$-type in the high school sample.

The impact on the proportion of employed individual working in flexible and non-flexible jobs is huge for types working mostly flexible jobs in the pre-policy regime. Only $0.007 \%$ of the $\alpha_{1}$-type in the college sample is working in flexible jobs in the pre-policy regime, while now $100 \%$ of them is forced to work in non-flexible jobs. Accordingly, the proportion of workers working in non-flexible jobs increases by about fourteen thousand times. The impact on profits on types with a high value of flexibility is large due to composition effects. For example, the average profit firms make on the $\alpha_{1}$-type in the college sample is a small fraction of the pre-policy profit, but this is because more $\alpha_{1}$-types work in flexible jobs after the policy change, generating a large increase in total profits.

To summarize, the impact of the presence of flexibility is large on some labor market outcomes (i.e., wages and hazard rates, redistribution of employment from flexible to nonflexible jobs) but negligible on others (unemployment).

\subsection{Counterfactual 2: Reduction of the cost of flexibility}

The second experiment considers policies that ease the provision of flexible jobs by reducing their cost. We implement a reduction of $k$ to one half of its estimated value. A lump-sum tax on all workers finances the cost reduction. A similar policy implemented at zero cost to both workers and employers leads to very similar results, and it is not reported. ${ }^{36}$

The model is characterized by the same structural parameters of the benchmark model plus the tax rate. The tax rate is endogenous, and it is defined as the tax rate necessary to support in equilibrium a cost reduction of $k$ to one half of its estimated value. The new equilibrium is analogous to the one obtained in the Section 3, with the addition of the derivation of the tax rate. Details of such derivation are in the Appendix A.4. To quickly illustrate the difference with respect to the benchmark case, we only report here the reservation match value in this new environment:

$$
x^{*}\left(h \mid \alpha_{j}\right)=\frac{\rho V_{U}\left(\alpha_{j}\right)+t-\alpha_{j} h}{1-k h}
$$

Because workers have to pay a tax when accepting a job, the direct impact of the tax

\footnotetext{
${ }^{36}$ Results of the no-tax policy experiment are reported in Flabbi and Moro (2010).
} 
rate on the productivity value at which a job becomes acceptable is positive. The overall impact depends on the direct impact and on the equilibrium impact of the tax rate on the value of unemployment $V_{U}\left(\alpha_{j}\right)$.

Because it is a is lump-sum tax, and it does not depend on the preferences for flexibility, the policy also impacts workers who do not value flexibility. We expect an increase in welfare for workers that value flexibility and a decrease for those who do not. The increase in welfare is due to the provision of flexibility at a lower cost: Because workers who value flexibility share this cost with the employers (due to bargaining) and with the workers who do not value flexibility (by the design of the lump-sum tax), any cost reduction is beneficial to them.

The results, reported in Table 5, show that the welfare effects are very small. The increase in welfare (first row of the table) for the $\alpha_{1}-$ and $\alpha_{2}$-types is only between 0.01 and 0.13 percentage points. The decrease in welfare for the $\alpha_{0}$-type is less than a thousandth of a percentage point. The result is due to the fact that the flexibility cost is very low in the benchmark model. Therefore, the cost reduction implied by the experiment is relatively modest.

An effect of the policy is the potential for efficiency gains. Because flexibility is cheaper, there is the potential for an increase of the range of productivities associated with acceptable jobs. To study whether this is the case, we have to look at the lower and upper bounds of this range. The impact on the upper bound is unambiguous. The upper bound is the reservation productivity value at which workers decide to work non-flexible jobs instead of flexible jobs. It is defined by equation (14) as the ratio between the preference for flexibility and the cost of its provision. Because the policy implies a lower cost of flexibility, the upper bound will be higher, contributing to a larger range. The impact on the lower bound is, instead, ambiguous. The lower bound is equal to the reservation productivity value at which jobs start to become acceptable, and it is defined in equation (33). After the policy, the numerator increases due to the increase in $\rho V_{U}(\alpha)$ and to the presence of the tax rate. The denominator increases due to the decrease in $k$. The overall impact is therefore ambiguous. However, we know from the first row of Table 5 that the increase in $\rho V_{U}(\alpha)$ is very small. Therefore, we expect the second effect to dominate, leading to a decrease in $x^{*}(h \mid \alpha)$. A lower reservation values means that some productivity ranges that were not acceptable before are now acceptable, leading to a decrease in unemployment. In the simulation, this decrease turns out to be negligible, with an order of magnitude of one thousandth of a percentage point on the type with the highest utility from flexibility. ${ }^{37}$

\footnotetext{
${ }^{37}$ On the other types valuing flexibility the change is so small as to approximate 100 up to the fifth decimal.
} 


\begin{tabular}{|c|c|c|c|c|c|c|c|c|}
\hline & \multicolumn{4}{|c|}{ College } & \multicolumn{4}{|c|}{ High School } \\
\hline & $\alpha_{0}$ & $\alpha_{1}$ & $\alpha_{2}$ & All & $\alpha_{0}$ & $\alpha_{1}$ & $\alpha_{2}$ & All \\
\hline \multirow[t]{2}{*}{$\rho V_{U}(\alpha)$} & 99.9999 & 100.01 & 100.13 & 100.01 & 99.9999 & 100.08 & 100.06 & 100.03 \\
\hline & \multicolumn{8}{|c|}{ Workers in non-flexible jobs } \\
\hline Mean wage & 99.72 & 179.00 & 148.01 & 102.72 & 100.02 & 148.56 & 181.01 & 98.93 \\
\hline St. dev. wages & 100.91 & 118.70 & 99.37 & 109.62 & 100.83 & 102.69 & 143.28 & 104.25 \\
\hline \multirow[t]{2}{*}{$\%$ of workers } & $=$ & 0.24 & 31.73 & 85.47 & $=$ & 23.47 & 2.46 & 85.06 \\
\hline & \multicolumn{8}{|c|}{ Workers in flexible jobs } \\
\hline Mean wage & . & 99.68 & 150.95 & 96.05 & . & 140.53 & 108.09 & 114.17 \\
\hline St. dev. wages & . & 99.31 & 237.94 & 81.47 & . & 234.98 & 134.74 & 118.95 \\
\hline \multirow[t]{2}{*}{$\%$ of workers } & 0 & 100.01 & 259.07 & 158.57 & 0 & 250.14 & 106.70 & 151.77 \\
\hline & \multicolumn{8}{|c|}{ Unemployed workers } \\
\hline Avg. unempl. dur. & 100.0001 & 99.9985 & 100.00 & 99.9998 & 100.0002 & 100.0001 & 100.00 & 100.0004 \\
\hline \multirow[t]{2}{*}{ Unempl. rate } & 100.0001 & 99.9986 & 100.00 & 99.9998 & 100.0001 & 100.0001 & 100.00 & 100.0003 \\
\hline & \multicolumn{8}{|c|}{ Firms' profits } \\
\hline Avg. (non-flexible) & 99.60 & 186.70 & 153.02 & 100.19 & 100.03 & 164.20 & 187.84 & 98.67 \\
\hline Total (non-flexible) & 99.60 & 169.73 & 48.63 & 85.64 & 100.03 & 38.62 & 6.36 & 83.94 \\
\hline Avg. (flexible) & . & 99.29 & 165.58 & 118.59 & . & 177.86 & 109.93 & 114.41 \\
\hline Total (flexible) & r & 99.30 & 428.62 & 188.06 & $\cdot$ & 444.51 & 117.30 & 173.58 \\
\hline
\end{tabular}

Table 5: Counterfactual 2: half flexibility cost financed by lump-sum tax. Benchmark model $=100)$, "=" refers to no change, "." refers to missing observations.

Because flexibility is cheaper and preferences are unchanged, we expect a transfer of employed workers from non-flexible jobs to flexible jobs. We also expect a greater in-flow to employment in flexible jobs from unemployment because the reservation productivity value at which workers will accept a flexible job is lower. As a result, the proportion of the employed working in flexible jobs increases. This is the first margin where we observe large effects. The seventh row of Table 5 shows that the increase is large (about 2 and half times) for the $\alpha_{2}$-type in the college sample and the $\alpha_{1}$-type in the high-school sample. These are types that value flexibility but still had more than half of the workers employed in non-flexible jobs in the benchmark model. The increase is smaller on the other two types valuing flexibility because almost all the workers were already employed in flexible jobs in the benchmark model.

The equilibrium impact on average wages is complex and takes place through five different channels. The first three channels lead to an increase in average wages in both flexible and non-flexible jobs. First, the lower cost of flexibility has a positive impact on wages be- 
cause the savings generated by the lower cost are split between workers and firms. Second, the equilibrium effect on the reservation wage is positive because the reservation wage is directly proportional to $\rho V_{U}(\alpha)$, which is increasing. Third, the composition in terms of productivity of workers working in flexible and non-flexible jobs is changing. The transition from non-flexible jobs to flexible jobs involves productivity ranges that are low with respect to non-flexible jobs in the benchmark model but high with respect to flexible jobs in the benchmark model. Therefore, the average wage will increase in flexible jobs because of the in-flow of high productivity workers and will also increase in non-flexible jobs because only the most productive workers will remain there. The fourth channel works through the lower reservation productivity value at which workers accept a flexible job. Because the reservation productivity value is lower, there is an in-flow of relatively low productivity workers into flexible jobs, leading to a negative impact on the average wage of workers in flexible jobs. The fifth and last channel is the presence of the tax. However, the tax generates a negligible impact in labor market outcomes because the cost of flexibility is very low. Therefore, the tax required to finance it is extremely low.

The results show that the first three channels dominate on all types with the exception of type $\alpha_{1}$ in the college sample. Average wages increase by about 50 percent or more in non-flexible jobs for both $\alpha_{1}$ and $\alpha_{2}$ types on both the college and high-school sample. Wages also increase in flexible jobs: by about 50 percent on type $\alpha_{2}$ in the college sample and by about 40 percent on type $\alpha_{1}$ in the high-school sample. For the college sample type $\alpha_{1}$, they decrease slightly (see the fifth row and second column of Table 5). Almost all workers of this type were employed in flexible jobs in the pre-policy regime; therefore, they are the most sensible to the wage compression due to the lower reservation productivity value (the fourth channel described above).

There are also economically significant impacts on profits. Starting with $\alpha_{2}$-type, workers with a college education, we observe that the average profits in non-flexible jobs increase. The increase is due to the redistribution of workers from non-flexible jobs to flexible jobs: with respect to the pre-policy environment, fewer but more productive matches are realized without flexibility. Therefore, overall profits will decrease, and average profit will increase. Over this type of workers, the average profits at flexible jobs also increase. This is because the additional surplus generated by the lower cost of flexibility is not fully appropriated by the worker, but it is partially distributed to the firm. The only type over which profits do not increase is type $\alpha_{1}$ in the college sample. Similarly to what happens on wages, the reservation productivity value at which jobs become acceptable decreases, leading to lower average and total profits. 
One general conclusion from the policy experiments is that the impacts are generally small, due to the relatively low utility value associated with flexibility. However, despite the small magnitude of the change in policies we are proposing, there is a large effect on wages. If the policy objective is to impact the wage structure, then policies aimed at reducing the cost of providing flexibility could be particularly effective. Moreover, if men had significantly lower preferences for flexibility - as some anecdotal evidence seems to indicate - then these

policies would have the potential to reduce the wage gap because they would increase female wages proportionally more than male wages.

\section{Conclusion}

In this paper, we estimate the parameters of a dynamic search model of the labor market in which workers and firms bargain over wages and the provision of flexibility. We maintain the narrow definition of flexibility most frequently found in the literature - flexibility as the availability of part-time work - and show that women value this amenity.

In our estimates, we also find that college graduates and high-school graduates value flexibility differently. College graduates place higher value on having flexible jobs. Moreover, we find that jobs requiring a college education can provide flexibility at a lower cost. Because women might also choose schooling to accommodate their preference for job flexibility, we speculate that this might explain some of the observed differences in schooling achievements between men and women.

The counterfactual experiments reveal that the impact of flexibility is quite substantial on some labor market outcomes (i.e., wages and hazard rates, the distribution of employment between flexible and non-flexible jobs) but negligible on others (notably, unemployment). For example, without flexibility, for college-educated women that value flexibility the most, the average wage would be $74 \%$ lower, while the unemployment rate would be at most $0.06 \%$ higher than in the benchmark environment with flexibility. We infer from our experiments that policies reducing the cost of flexibility provision could be very effective in changing the realized wage distribution at little cost in terms of employment.

Our approach presents four main limitations. First, in the empirical application of our model, we define flexible jobs using part-time jobs. A more appropriate definition should also capture the option of organizing work time in a flexible way.

Second, we estimate the model by schooling groups and we find significant differences between them. We did not, however, integrate a schooling decision in the model and in the estimation procedure. We think devoting future work to filling this gap is particularly 
promising to test our conjecture that expectations on future job amenities, such as flexibility, are important components of the schooling choices of women.

Third, employers and workers in our model are very stylized. In particular, we assume a homogenous cost of providing flexibility, and workers are heterogeneous only in education and preference for flexibility. Estimating heterogeneous costs and correlations between costs and industries could help explain why we observe different preferences across different skill levels and could deepen our understanding of the feedback of the labor market on schooling choices. Just as we find that different levels of schooling are correlated with preferences for flexibility, we could find that different types of jobs or schooling (e.g., college majors) are correlated with preferences for flexibility because they increase the likelihood of working in jobs and industries that provide flexibility at low cost.

Fourth, we have found a strong impact of flexibility on wages and a significant correlation between preference for flexibility and level of schooling. A large amount of literature on gender differentials on both variables currently points to a puzzle: Recent data on U.S. workers show women earning lower wages than men, despite having a positive schooling differential. Results from the counterfactuals reveal that changes in the provision of flexibility (e.g., through a subsidization of its cost) have a large differential impact for people that value flexibility differently. Therefore, a higher preference for flexibility for women with respect to men (if proved) could potentially explain a large portion of the gender-wage differential. Exploring this conjecture requires estimating the model for a sample of men. Our sample does not include enough males working in flexible jobs to provide reliable estimates of their preferences for flexibility. We hope that a more complete data set providing a better definition of flexibility (and possibly more detailed schooling and firms information) will also generate enough data variation to estimate the model on a sample of men.

\section{References}

[1] Altonji, J., and C. Paxson (1988) "Labor Supply Preferences, Hours Constraints, and Hours-Wage Trade-offs", Journal of Labor Economics, 6(2): 254-276.

[2] Becker, G. (1967) Human Capital and the Personal Distribution of Income, Ann Arbor, MI: University of Michigan Press.

[3] Blank, R. (1990) "Are Part-Time Jobs Bad Jobs?", in G. Burtless (ed.) A Future of Lousy Jobs? The Changing Structure of U.S. Wages. Washington, D.C.: Brooking Institution. 
[4] Blau, D. (1991) Search for Nonwage Job Characteristics: A Test for Reservation Wage Hypothesis", Journal of Labor Economics, 9(2): 186-205.

[5] Bloemen, H. (2008), "Job Search, Hours Restrictions, and Desired Hours of Work", Journal of Labor Economics, 26(1): 137-179.

[6] Bowlus, A. (1997), "A Search Interpretation of Male-Female Wage Differentials", Journal of Labor Economics, 15(4), pg. 625-657.

[7] Burdett, K., and D. Mortensen (1998), "Wage Differentials, Employer Size, and Unemployment", International Economic Review, 39(2), 257-273.

[8] Chiappori, P-A., M. Iyigun, and Y. Weiss (2006), "Investment in Schooling and the Marriage Market", IZA Discussion Paper 2454

[9] Dey, M., and C. Flinn (2005), "An Equilibrium Model of Health Insurance Provision and Wage Determination", Econometrica, 73: 571-627.

[10] Eckstein, Z., and G. van den Berg (2007), "Empirical labor search: A survey", Journal of Econometrics, 136: 531-564.

[11] Eckstein, Z., and K. Wolpin (1995), "Duration to First Job and the Return to Schooling: Estimates from a Search-Matching Model", The Review of Economic Studies, 62(2): 263-286.

[12] Eckstein, Z., and K. Wolpin (1999), "Estimating the Effect of Racial Discrimination on First Job Wage Offers", The Review of Economics and Statistics, 81(3): 384-392.

[13] Flabbi, L. (2010), "Gender Discrimination Estimation in a Search Model with Matching and Bargaining", International Economic Review, 51(3): 745-783.

[14] Flabbi, L., and A. Moro (2010), "The Effect of Job Flexibility on Female Labor Market Outcomes: Estimates from a Search and Bargaining Model", IZA Discussion Paper 4829 .

[15] Flinn, C. (2006), "Minimum Wage Effects on Labor Market Outcomes under Search, Bargaining and Endogenous Contact Rates", Econometrica, 73: 1013-1062.

[16] Flinn, C., and J. Heckman (1982), "New Methods in Analyzing Structural Models of Labor Market Dynamics", Journal of Econometrics, 18: 115-168. 
[17] Ge, S. (2008), "Women's College Decisions: How Much Does Marriage Matter?", mimeo, Virginia Tech.

[18] Golden, L. (2001), "Flexible Work Schedules: What Are We Trading Off to Get Them?", Monthly Labor Review, March.

[19] Gronberg, T., and R. Reed (1988), "Estimating Workers' Marginal Willingness to Pay for Job Attributes using Duration Data", Journal of Human Resources, 29: 911-931.

[20] Hwang, H., D. Mortensen, and R. Reed (1998), "Hedonic Wages and Labor Market Search", Journal of Labor Economics, 16(4): 815-847.

[21] Lang K. and S. Majumdar (2004), "The Pricing of Job Characteristics When Markets Do Not Clear: Theory and Policy Implications", International Economic Review, 45(4): 1111-1128.

[22] Moffitt, R. (1984) "The Estimation of a Joint Wage-Hours Labor Supply Model", Journal of Labor Economics, 2(4): 550-566.

[23] Postel-Vinay, F. and J-M Robin (2002), "Equilibrium Wage Dispersion with Worker and Employer Heterogeneity", Econometrica, 70(6), 2295-2350.

[24] Rosen, S. (1974), "Hedonic Prices and Implicit Markets: Product Differentiation in Pure Competition", Journal of Political Economy, 82: 34-55.

[25] Rosen, S. (1986), "The Theory of Equalizing Differences" in: Handbook of Labor Economics, V. 1 (O. Ashenfelter and R. Layard, eds.), Amsterdam: North-Holland.

[26] Scandura, T., and M. Lankau (1997), "Relationship of gender, family responsability and flexible work hours to organizational commitment and job satisfaction", Journal of Organizational Behavior, 18: 377-391.

[27] Topel, R. (1986), "Local Labor Markets", Journal of Political Economy, 94: S111-S143.

[28] Usui, E. (2006), "Gender Occupational Segregation in an Equilibrium Search Model", mimeo, Wayne State University.

[29] Wolpin, K. (1990), Estimating a Structural Search Model: The Transition from School to Work". Econometrica 55 (July 1987), 801-17 


\section{A Appendix}

\section{A.1 Derivation of Value Functions}

The value of employment at wage $w$ and flexibility $h$ for an agent with preference $\alpha$ working at a firm with flexibility cost $k$ is given by the following discrete time approximation:

$$
\begin{aligned}
V_{E}(w, h ; \alpha, k) & =(w+\alpha h) \Delta t+ \\
& +\rho(\Delta t)\left[(1-\eta \Delta t) V_{E}(w, h ; \alpha, k)+\eta \Delta t V_{U}(\alpha)+o(\Delta t)\right]
\end{aligned}
$$

where $\Delta t$ denotes a time span. This expression states that the value of employment is given by the utility received in the entire period plus the discounted expected value of remaining at the job or of falling in the unemployment state. Other possible events are happening with a negligible probability $o(\Delta t)$. Assuming $\rho(\Delta t)=(1+\rho \Delta t)^{-1}$, rearranging terms and dividing both sides by $\Delta t$, we obtain:

$$
\begin{aligned}
\frac{(1+\rho \Delta t)}{\Delta t} V_{E}(w, h ; \alpha, k) & =(w+\alpha h) \Delta t \frac{(1+\rho \Delta t)}{\Delta t}+ \\
+ & \frac{(1-\eta \Delta t)}{\Delta t} V_{E}(w, h ; \alpha, k)+\frac{\eta \Delta t}{\Delta t} V_{U}(\alpha)+\frac{o(\Delta t)}{\Delta t}
\end{aligned}
$$

Since the Poisson process assumption implies that $\lim _{\Delta t \rightarrow 0} \frac{o(\Delta t)}{\Delta t}=0$, when $\Delta t \longrightarrow 0$ the previous expression converges to:

$$
\rho V_{E}(w, h ; \alpha, k)=w+\alpha h-\eta V_{E}(w, h ; \alpha, k)+\eta V_{U}(\alpha)
$$

After collecting terms, this equation is equivalent to (3).

The value of unemployment for an agent with preference $\alpha$ is given by the following discrete time approximation:

$$
\begin{aligned}
V_{U}(\alpha) & =b(\alpha) \Delta t+ \\
& +\rho(\Delta t)\left\{(1-\lambda \Delta t) V_{U}(\alpha)+\lambda \Delta t \int \max \left[V_{E}(w, h ; \alpha, k), V_{U}(\alpha)\right] d G(x)+o(\Delta t)\right\}
\end{aligned}
$$

This expression states that the value of unemployment is given by the total (dis)utility from unemployment over the period, equal to $b(\alpha) \Delta t$, and by the fact that after a period $\Delta t$, two main events may happen: not meeting any firm and remaining unemployed or meeting a firm, extracting a match-specific productivity value $x$ and deciding whether to accept the 
job offer or not. We can proceed as with the derivation of $V_{E}$, obtaining:

$$
\begin{aligned}
\frac{(1+\rho \Delta t)}{\Delta t} V_{U}(\alpha) & =b(\alpha) \Delta t \frac{(1+\rho \Delta t)}{\Delta t}+\frac{(1-\lambda \Delta t)}{\Delta t} V_{U}(\alpha)+ \\
& +\frac{\lambda \Delta t}{\Delta t} \int \max \left[V_{E}(w, h ; \alpha, k), V_{U}(\alpha)\right] d G(x)+\frac{o(\Delta t)}{\Delta t}
\end{aligned}
$$

Computing the limit to continuous time, this expression becomes:

$$
\rho V_{U}(\alpha)=b(\alpha)-\lambda V_{U}(\alpha)+\lambda \int \max \left[V_{E}(w, h ; \alpha, k), V_{U}(\alpha)\right] d G(x)
$$

leading to equation (4) when we collect terms.

Finally, the value of a filled job for a firm with technology $k$ paying a wage $w$, offering flexibility $h$ to an agent with preference $\alpha$ is:

$$
\begin{aligned}
V_{F}(p r, h ; \alpha, k) & =[(1-k h) x-w] \Delta t+ \\
& +\rho(\Delta t)\left[(1-\eta \Delta t) 0+\eta \Delta t V_{F}(p r, h ; \alpha, k)+o(\Delta t)\right]
\end{aligned}
$$

Notice that the dependence on the worker's preference is through the wage schedule,which depends on $\alpha$ after the bargaining game is solved. Applying the assumption on the discount function $\rho(\Delta t)$ and rearranging we get:

$$
\frac{(1+\rho \Delta t)}{\Delta t} V_{F}(p r, h ; \alpha, k)=[(1-k h) x-w] \frac{(1+\rho \Delta t)}{\Delta t}+\frac{\eta \Delta t}{\Delta t} V_{F}(p r, h ; \alpha, k)+\frac{o(\Delta t)}{\Delta t}
$$

and taking limits to continuous time:

$$
\rho V_{F}(p r, h ; \alpha, k)=[(1-k h) x-w]+\eta V_{F}(p r, h ; \alpha, k)
$$

leading to equation (5) when we collect terms.

\section{A.2 Proof of Proposition 1}

Proof. By definition of the reservation values:

$$
x^{* *} \leq x^{*}(0) \Longleftrightarrow \frac{\alpha}{k} \leq \rho V_{U}(\alpha) \Longleftrightarrow \alpha \leq k \rho V_{U}(\alpha)
$$

Also, by definition of the reservation values, we obtain:

$$
x^{*}(0) \leq x^{*}(1) \Longleftrightarrow \rho V_{U}(\alpha) \leq \frac{\rho V_{U}(\alpha)-\alpha}{1-k} \Longleftrightarrow \alpha \leq k \rho V_{U}(\alpha)
$$


proving the claim.

\section{A.3 Matched Moments}

We match mean unemployment duration and the proportion of individuals in unemployment exactly to compute the hazard rate and $\rho$. To estimate the other parameters, we match various moments of portions of five interquantiles of the flexible and non-flexible workers' wage distributions delimited by percentiles $0,20,40,60,80$, and 100 of the non-flexible workers' wage distribution. The moments we match are the mean and standard deviation of wages of workers in non-flexible jobs, the fraction of workers in flexible jobs, and the mean and standard deviation of wages of workers in flexible jobs. The following table illustrates the moments in the data and simulated moments at the estimated parameter values.

\begin{tabular}{l|cccc|cccccc} 
& \multicolumn{3}{|c}{ Non-flexible jobs } & \multicolumn{3}{c}{ Flexible jobs } \\
Sample & \multicolumn{2}{|c}{ Mean wages } & St. dev. wages & Prop. workers & Mean wages* & St. dev. wages* \\
& Estim. & Data & Estim. & Data & Estim & Data & Estim. & Data & Estim. & Data \\
\hline All College & 23.715 & 23.410 & 11.302 & 10.360 & 0.191 & 0.200 & 21.836 & 22.490 & 12.784 & 14.152 \\
Quintile 1 & 12.297 & 12.032 & 1.976 & 2.273 & 0.311 & 0.311 & 3.495 & 3.447 & 2.491 & 2.470 \\
Quintile 2 & 16.858 & 17.085 & 1.124 & 1.106 & 0.118 & 0.122 & 2.020 & 2.131 & 1.798 & 1.911 \\
Quintile 3 & 21.141 & 21.134 & 1.270 & 1.352 & 0.128 & 0.071 & 2.701 & 1.528 & 2.374 & 1.469 \\
Quintile 4 & 26.587 & 26.574 & 1.857 & 2.080 & 0.163 & 0.190 & 4.368 & 5.037 & 3.683 & 4.144 \\
Quintile 5 & 39.222 & 39.910 & 7.783 & 8.196 & 0.197 & 0.195 & 7.819 & 8.021 & 6.483 & 6.714 \\
\hline All High Sc. & 13.933 & 13.879 & 6.097 & 5.923 & 0.218 & 0.219 & 10.512 & 10.294 & 3.918 & 4.279 \\
Quintile 1 & 7.321 & 7.532 & 1.179 & 1.253 & 0.379 & 0.369 & 2.744 & 2.765 & 1.768 & 1.798 \\
Quintile 2 & 10.301 & 10.091 & 0.718 & 0.731 & 0.276 & 0.277 & 2.757 & 2.769 & 2.008 & 2.026 \\
Quintile 3 & 12.718 & 12.735 & 0.736 & 0.770 & 0.145 & 0.144 & 1.846 & 1.843 & 1.590 & 1.609 \\
Quintile 4 & 15.640 & 15.559 & 1.004 & 1.139 & 0.146 & 0.144 & 2.273 & 2.223 & 1.956 & 1.945 \\
Quintile 5 & 22.452 & 22.392 & 3.974 & 4.137 & 0.089 & 0.084 & 1.760 & 1.780 & 1.622 & 1.703
\end{tabular}

*Because some quintiles may not display any worker in flexible jobs for some parameter values and because identification relies on the fractions of flexible and non-flexible job workers with overlapping wage support, means and standard deviations of wages in flexible jobs were multiplied by the corresponding fraction of workers in flexible jobs (except for the row displaying moments for all workers). 


\section{A.4 Derivation of Lump-sum Tax in Counterfactual Experiment 2}

The equilibrium characterization of this model is analogous to that obtained in Section 3, but we also need to compute the tax rate $t$. Wages and profits result from bargaining over the surplus. The surplus - represented in the pre-policy environment by equation (6) - now becomes:

$$
S(x, w, h ; \alpha, k)=\frac{1}{\rho+\eta}\left[w-t+\alpha h-\rho V_{U}(\alpha)\right]^{\beta}\left[\left(1-k^{\prime} h\right) x-w\right]^{(1-\beta)}
$$

leading to the following wage schedule:

$$
\widetilde{w}(x, h)=\beta\left(1-k^{\prime} h\right) x+(1-\beta)\left[\rho V_{U}(\alpha)+t-\alpha h\right]
$$

This is the wage schedule that corresponds to equation (7) in the pre-policy environment. As in the benchmark case, the model can be written recursively. The value of unemployment equations used to compute the reservation values are, for $\alpha_{0}$ :

$$
\rho V_{U}\left(\alpha_{0}\right)=b\left(\alpha_{0}\right)+\frac{\lambda \beta}{\rho+\eta} \int_{\rho V_{U}\left(\alpha_{0}\right)+t}\left[x-\rho V_{U}\left(\alpha_{0}\right)-t\right] d G(x \mid \mu, \sigma)
$$

and for $\alpha_{1}, \alpha_{2}$ :

$$
\begin{aligned}
\rho V_{U}\left(\alpha_{j}\right)= & b\left(\alpha_{j}\right)+\frac{\lambda \beta}{\rho+\eta} \int_{\frac{\rho V_{U}\left(\alpha_{j}\right)+t-\alpha_{j}}{1-k^{\prime}}}^{\frac{\alpha_{j}}{k^{\prime}}}\left[x-\frac{\rho V_{U}\left(\alpha_{j}\right)+t-\alpha_{j}}{1-k^{\prime}}\right] d G(x \mid \mu, \sigma) \\
& +\frac{\lambda \beta}{\rho+\eta} \int_{\frac{\alpha_{j}}{k^{\prime}}}\left[x-\rho V_{U}\left(\alpha_{j}\right)+t\right] d G(x \mid \mu, \sigma)
\end{aligned}
$$

where we have already imposed the optimal wage schedule and the optimal decision rule based on the reservation values:

$$
x^{*}\left(h \mid \alpha_{j}\right)=\frac{\rho V_{U}\left(\alpha_{j}\right)+t-\alpha_{j} h}{1-k^{\prime} h}
$$

Given these equations the equilibrium is defined as in the benchmark model. To compute the endogenous tax rate we need to know in equilibrium the proportion of workers who are employed and unemployed. To obtain these values, it is useful to define the hazard rate from unemployment to employment in flexible and non-flexible jobs. Given the stationarity of the model and the Poisson process assumption, the hazard rates are constant and equal to the probability of receiving an offer multiplied by the probability to accept it. For types 
$\alpha_{1}$ and $\alpha_{2}$, the hazard rate from unemployment to employment in flexible jobs is:

$$
r\left(h=1 \mid \alpha_{j}\right)=\lambda\left[G\left(\frac{\alpha_{j}}{k^{\prime}} \mid \mu, \sigma\right)-G\left(\frac{\rho V_{U}\left(\alpha_{j}\right)+t-\alpha_{j}}{1-k^{\prime}} \mid \mu, \sigma\right)\right]
$$

For types $\alpha_{0}, \alpha_{1}$ and $\alpha_{2}$, the hazard rate from unemployment to employment in non-flexible jobs is:

$$
r\left(h=0 \mid \alpha_{j}\right)=\lambda\left(1-G\left[\rho V_{U}\left(\alpha_{0}\right)+t \mid \mu, \sigma\right]\right)
$$

By equating flow in and out unemployment, we obtain the steady state equilibrium rates of unemployment:

$$
\begin{aligned}
u\left(\alpha_{0}\right) & =\frac{\eta}{r\left(h=0, \alpha_{0}\right)+\eta} \\
u\left(\alpha_{j}\right) & =\frac{\eta}{\left[r\left(h=0, \alpha_{j}\right)+r\left(h=1, \alpha_{j}\right)\right]+\eta} ; \alpha_{j}=\alpha_{1}, \alpha_{2}
\end{aligned}
$$

We can then compute the total expense $(T E)$ to reduce the cost of providing flexibility by multiplying the per unit cost $\left(k-k^{\prime}\right)$ for the total mass of workers employed in flexible jobs:

$$
T E=\left(k-k^{\prime}\right)\left[\frac{r\left(h=1 \mid \alpha_{1}\right)}{\eta} u\left(\alpha_{1}\right) p_{1}+\frac{r\left(h=1 \mid \alpha_{2}\right)}{\eta} u\left(\alpha_{2}\right) p_{2}\right]
$$

All employed workers pay the total lump-sum tax $T T$, so it will be equal to:

$$
T T=t\left[\left(1-u\left(\alpha_{0}\right)\right) p_{0}+\left(1-u\left(\alpha_{1}\right)\right) p_{1}+\left(1-u\left(\alpha_{2}\right)\right) p_{2}\right]
$$

Notice that both $T E$ and $T T$ are a function of the tax rate because the equilibrium unemployment rate depends on $t$. By equating tax revenue with expenses, $\mathrm{TT}=\mathrm{TE}$, we obtain an implicit function of the tax rate $t$ that we can solve for $t$. 